Correction

\title{
Correction: Dillman et al. Review and Meta-Analysis of EVs: Embodied Emissions and Environmental Breakeven. Sustainability 2020, 12, 9390
}

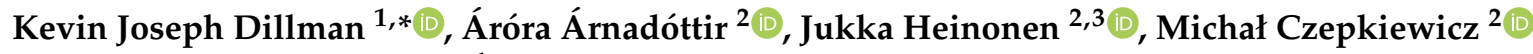 \\ and Brynhildur Davíosdóttir ${ }^{1}$ \\ 1 Department of Environment and Natural Resources, School of Engineering and Natural Sciences, \\ University of Iceland, 107 Reykjavík, Iceland; bdavids@hi.is \\ 2 Department of Civil and Environmental Engineering, School of Engineering and Natural Sciences, \\ University of Iceland, 107 Reykjavík, Iceland; ara32@hi.is (Á.Á.); heinonen@hi.is (J.H.); \\ michal.czepkiewicz@gmail.com (M.C.) \\ 3 Department of Built Environment, Aalto University, 00076 Aalto, Finland \\ * Correspondence: kjd2@hi.is
}

check for updates

Citation: Dillman, K.J.; Árnadóttir Á.; Heinonen, J.; Czepkiewicz, M.; Davíðsdóttir, B. Correction: Dillman et al. Review and Meta-Analysis of EVs: Embodied Emissions and Environmental Breakeven. Sustainability 2020, 12, 9390. Sustainability 2021, 13, 5195 https://doi.org/10.3390/su13095195

Received: 29 April 2021

Accepted: 4 May 2021

Published: 6 May 2021

Publisher's Note: MDPI stays neutral with regard to jurisdictional claims in published maps and institutional affiliations.

Copyright: (c) 2021 by the authors. Licensee MDPI, Basel, Switzerland. This article is an open access article distributed under the terms and conditions of the Creative Commons Attribution (CC BY) license (https:/ / creativecommons.org/licenses/by/ $4.0 /)$.
The authors would like to make the following corrections about the published paper [1]. The changes are as follows:

(1) Replacing affiliation 3:

Department of Built Environment, Aalto University, 00076 Aalto, Iceland with:

Department of Built Environment, Aalto University, 00076 Aalto, Finland

(2) Replacing the sentence in "Section 4.3. The Distances of Intersection Points (DIPs)" on page 16:

Additionally, the UK, Cyprus, and Greece saw breakeven points beyond the vehicles' assumed lifetime. The darker red the country, the greater the number of kilometers required to be driven to meet the DIP point. In the petrol case (Figure $7 \mathrm{~b}$ ), no countries saw a DIP greater than the vehicles' assumed lifetime. The minimum estimated DIPs were approximately 34,100 and $18,000 \mathrm{~km}$ for the diesel and petrol cases, respectively, which were both found in Iceland. France and the other Nordic countries follow not far behind Iceland.

with:

Additionally, only Cyprus saw breakeven points beyond the vehicles' assumed lifetime. The darker red the country, the greater the number of kilometers required to be driven to meet the DIP point. In the petrol case (Figure $7 \mathrm{~b}$ ), no countries saw a DIP greater than the vehicles' assumed lifetime. The minimum estimated DIPs were approximately 31,100 and $17,000 \mathrm{~km}$ for the diesel and petrol cases, respectively, which were both found in Iceland. France and the other Nordic countries follow not far behind Iceland.

(3) Replacing the sentence in "Section 4.4. Emissions Disparity (ED)" on page 16:

Figure 8a shows that in comparison with diesel vehicles, EVs are estimated to have more GHG emissions over their life cycle in seven countries. All countries that are not blue have a negative ED (Latvia, Estonia, Poland, Greece, Cyprus, Malta, and the UK).

with: 
Figure 8a shows that in comparison with diesel vehicles, EVs are estimated to have more GHG emissions over their life cycle in seven countries. All countries that are not blue have a negative ED (Latvia, Estonia, Poland, Greece, Cyprus, and Malta).

(4) Replacing the sentence in "Section 4.5. Maximum Production Emissions (MPEs)" on page 16:

Within the diesel case, it can be seen that the non-blue blue colored countries (Poland, Malta, and Latvia) require negative MPE's to be environmentally viable, obviously an unrealistic case.

with:

Within the diesel case, it can be seen that the only non-blue colored country is Latvia, where a negative MPE would be required to be environmentally viable, which is obviously an unrealistic case.

(5) As a continuation of this issue, the authors need to replace the original Figure 7:

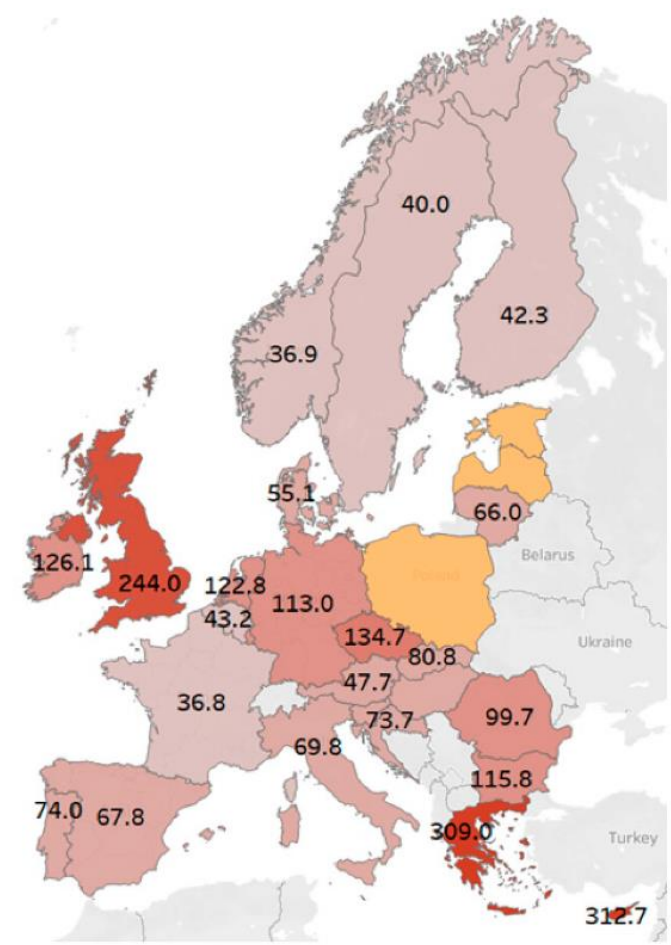

(a) Diesel DIP

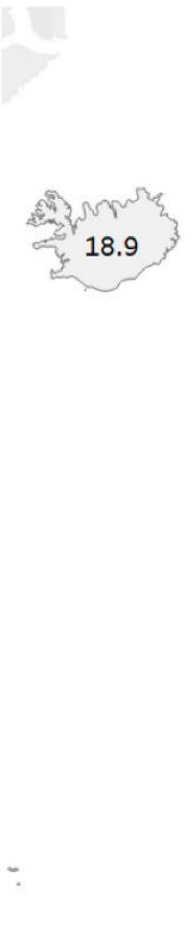

(b) Petrol DIP

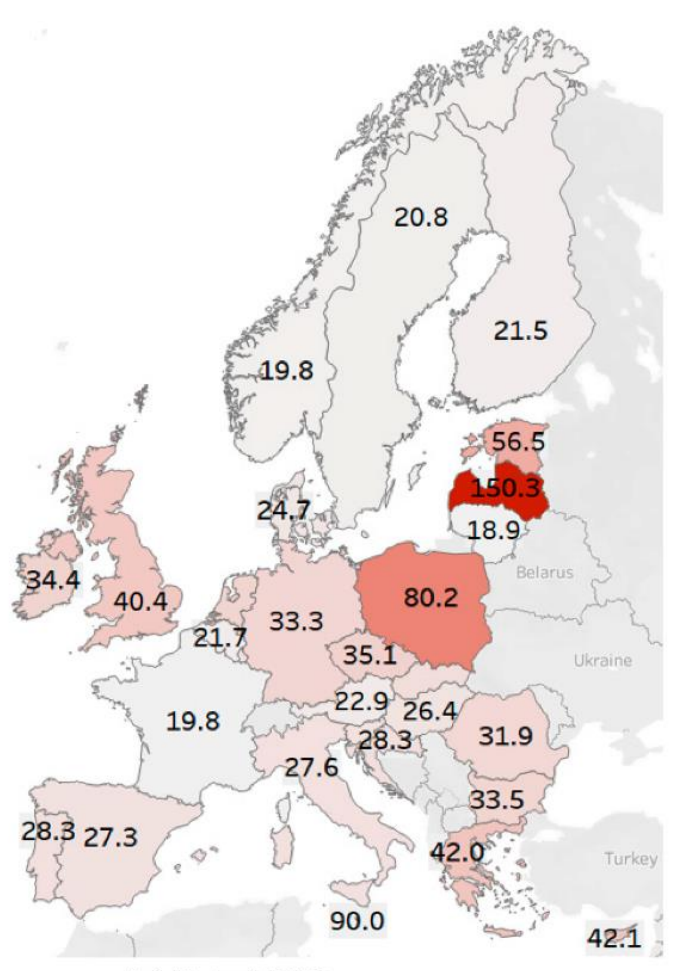

Figure 7. The distances of intersection points (DIPs; measured in thousands of kilometers) between an EV and (a) a diesel vehicle for comparison; (b) a petrol vehicle for comparison (in Figure 7a, the diesel DIP case, Malta does not intersect, and is thus highlighted in orange, but cannot be seen due to its relative size on the map).

with: 


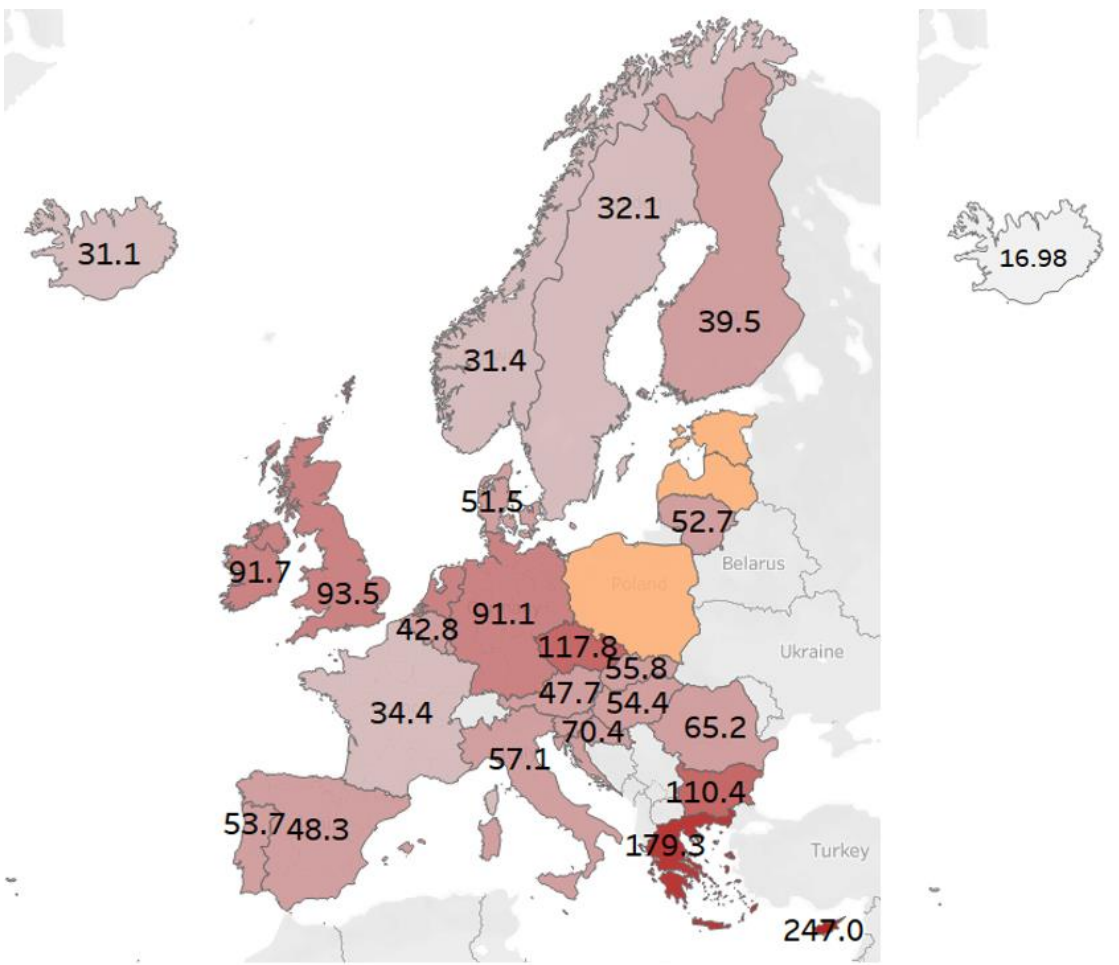

(a) Diesel DIP

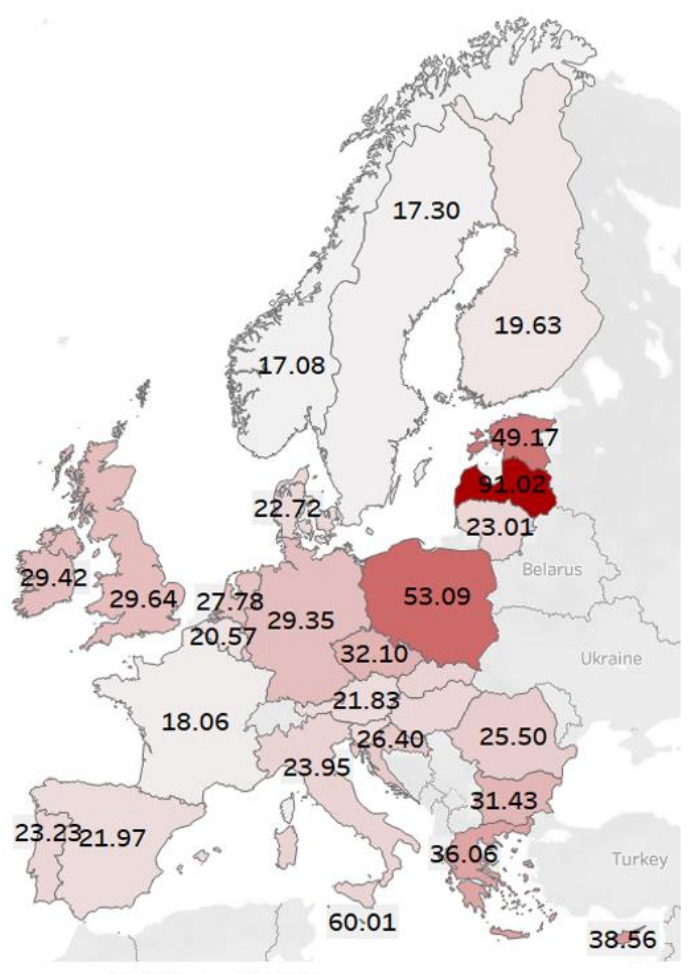

(b) Petrol DIP

Figure 7. The distances of intersection points (DIPs; measured in thousands of kilometers) between an EV and (a) a diesel vehicle for comparison; (b) a petrol vehicle for comparison (in Figure 7a, the diesel DIP case, Malta does not intersect, and is thus highlighted in orange, but cannot be seen due to its relative size on the map).

(6) As a continuation of this issue, the authors need to replace the original Figure 8:

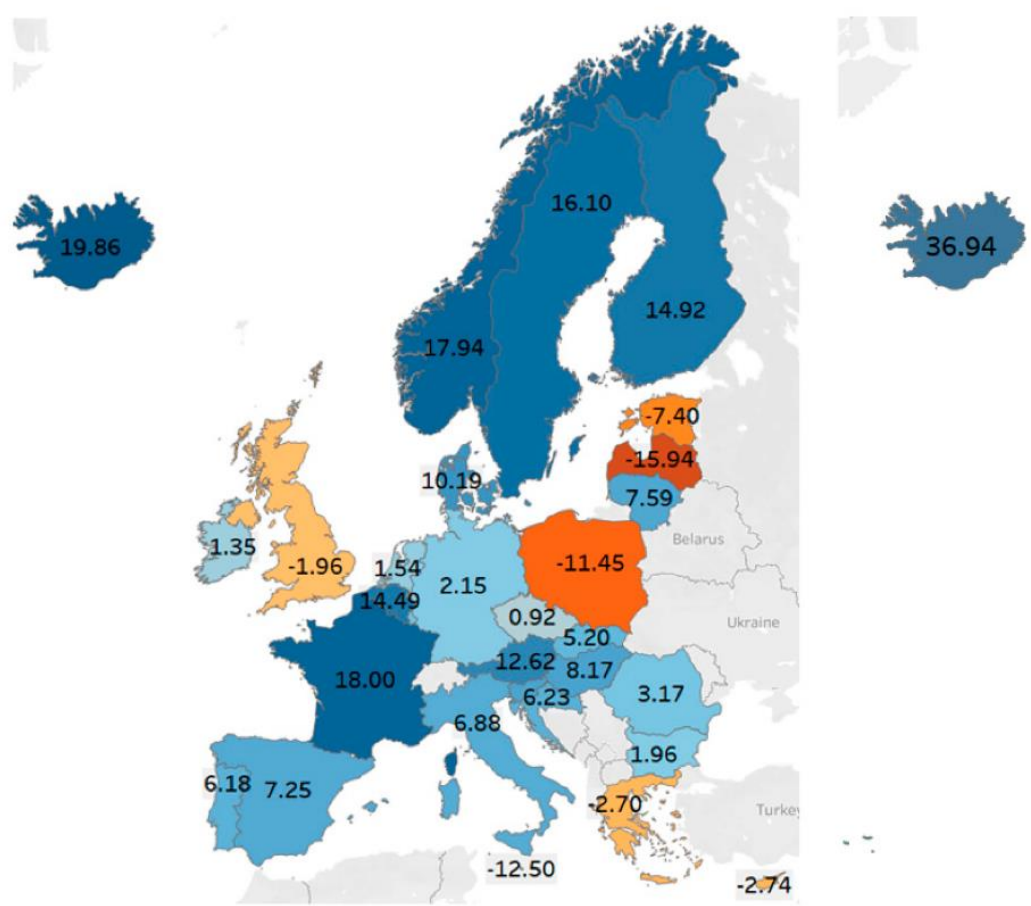

(a) Diesel ED

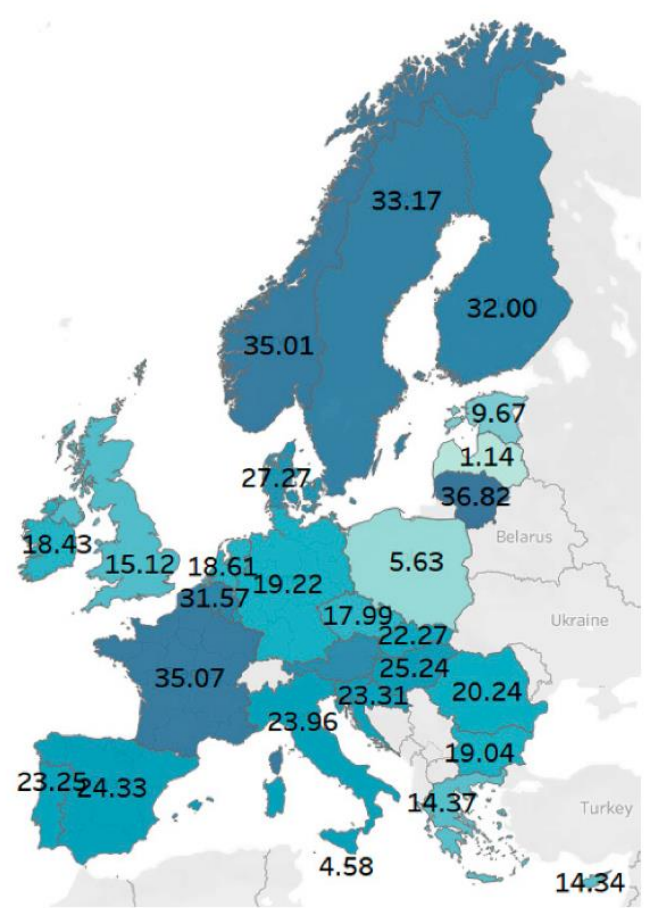

(b) Petrol ED

Figure 8. Emissions disparity (ED) (measured in $\mathrm{tCO}_{2} \mathrm{eq}$ ) between an $\mathrm{EV}$ and (a) a diesel vehicle for comparison; (b) a petrol vehicle for comparison. 
with:

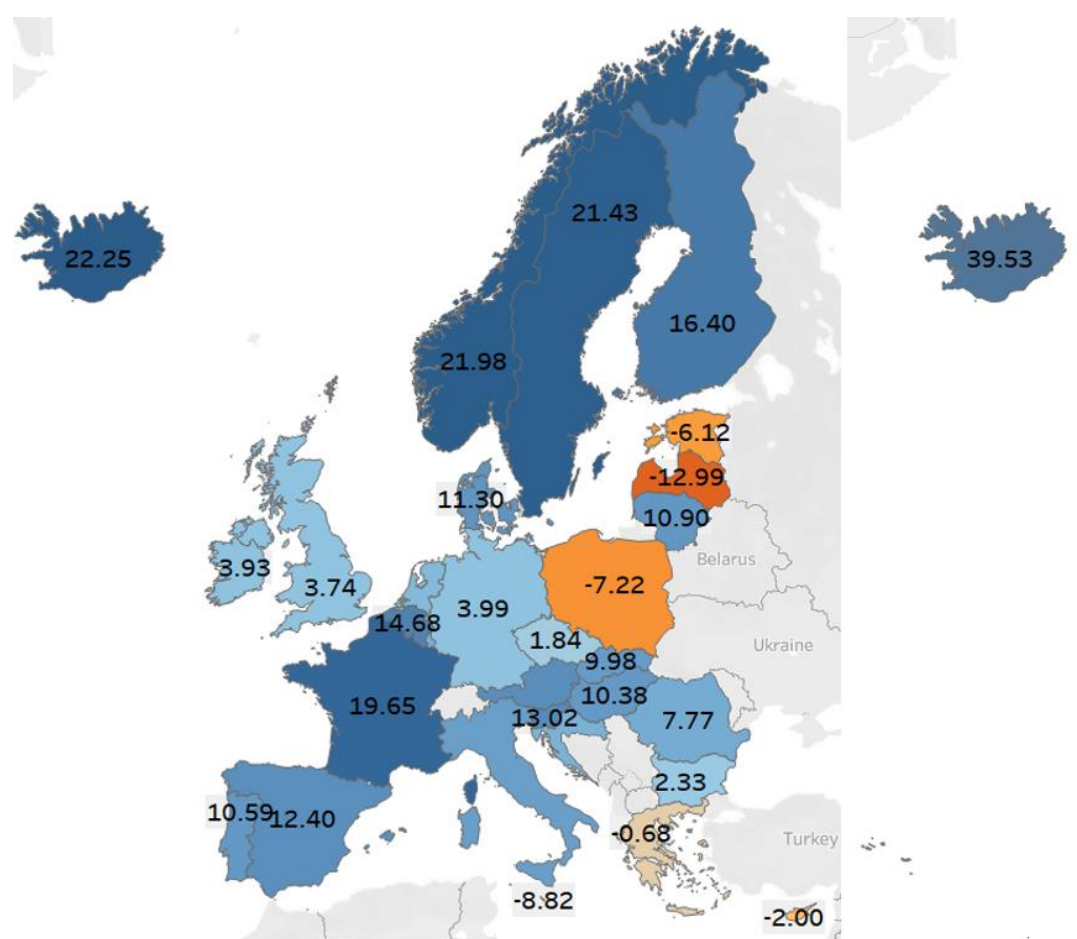

(a) Diesel ED

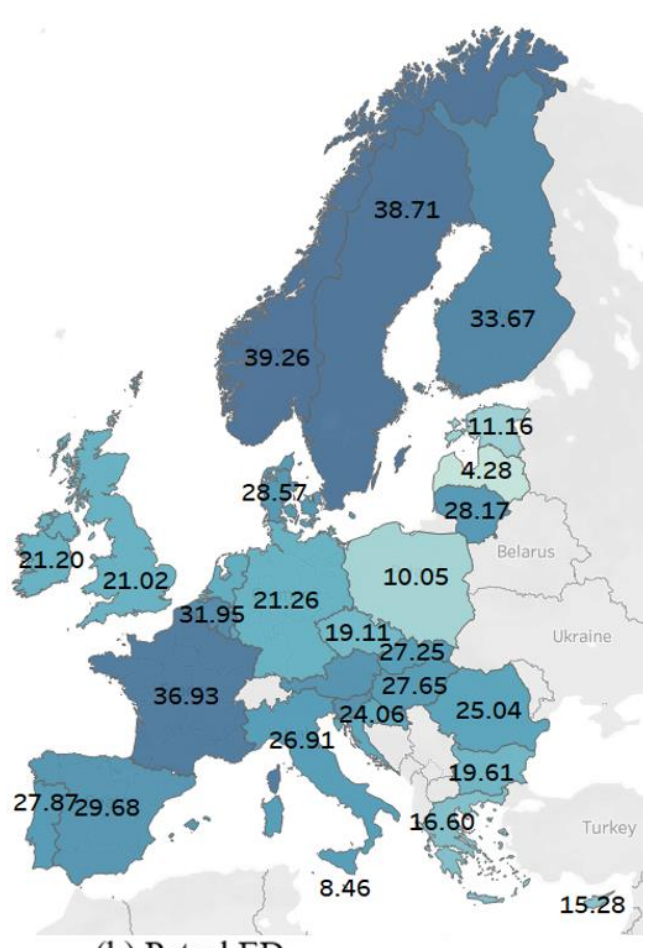

(b) Petrol ED

Figure 8. Emissions disparity (ED) (measured in $\mathrm{tCO}_{2} \mathrm{eq}$ ) between an EV and (a) a diesel vehicle for comparison; (b) a petrol vehicle for comparison.

(7) As a continuation of this issue, the authors need to replace the original Figure 9:

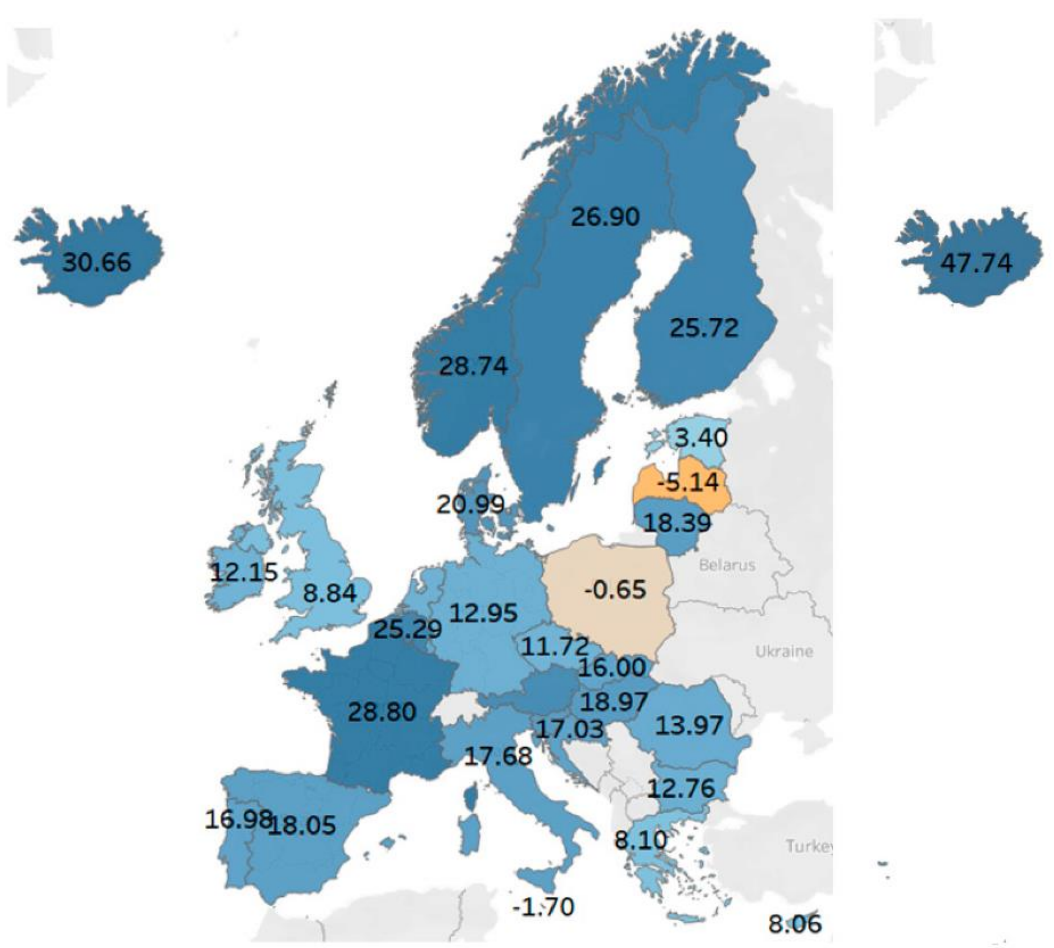

(a) Diesel MPE

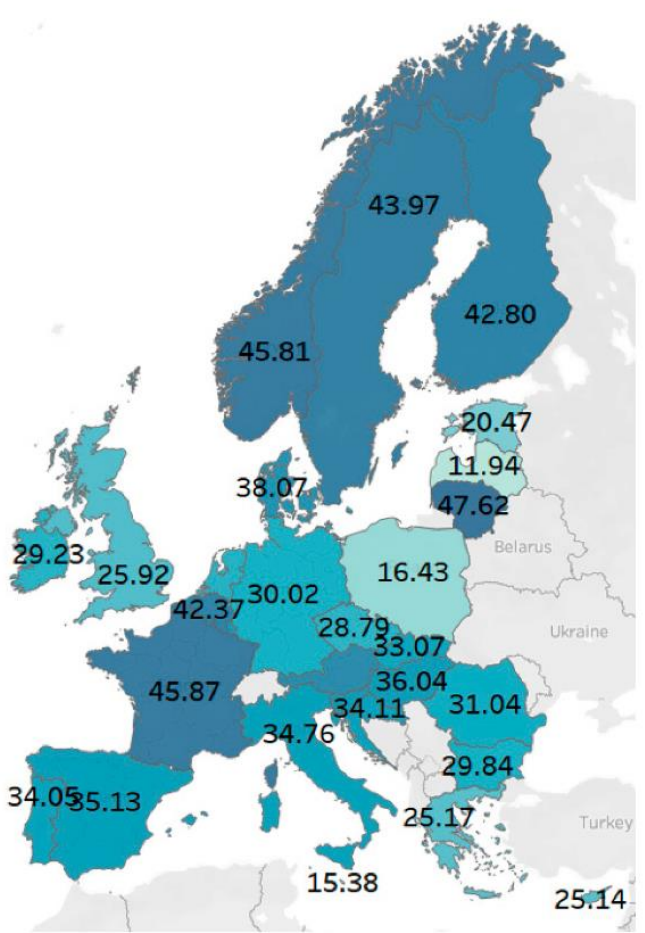

(b) Petrol MPE

Figure 9. Maximum production emissions (MPEs; measured in $\mathrm{tCO}_{2} \mathrm{eq}$ ) of an EV to environmentally outperform (a) a diesel vehicle for comparison; (b) a petrol vehicle for comparison. 
with:

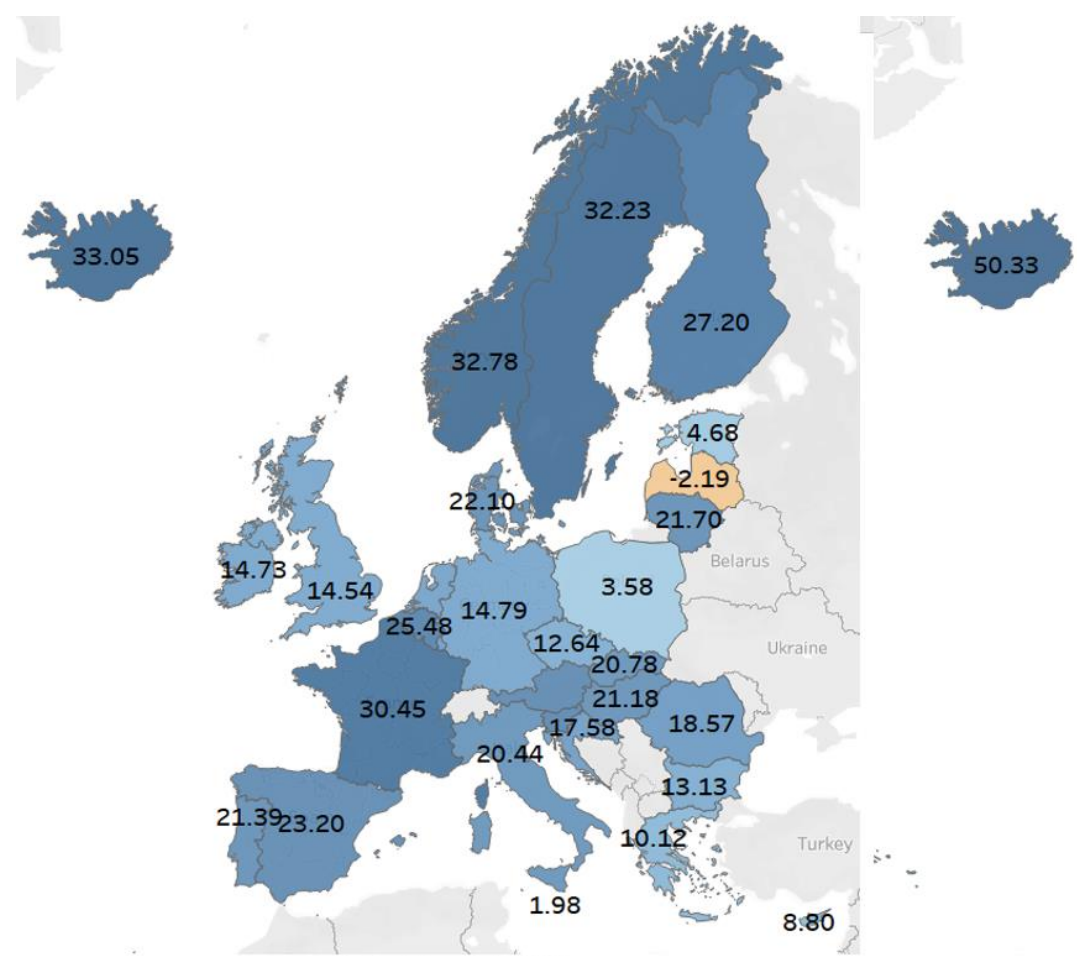

(a) Diesel MPE

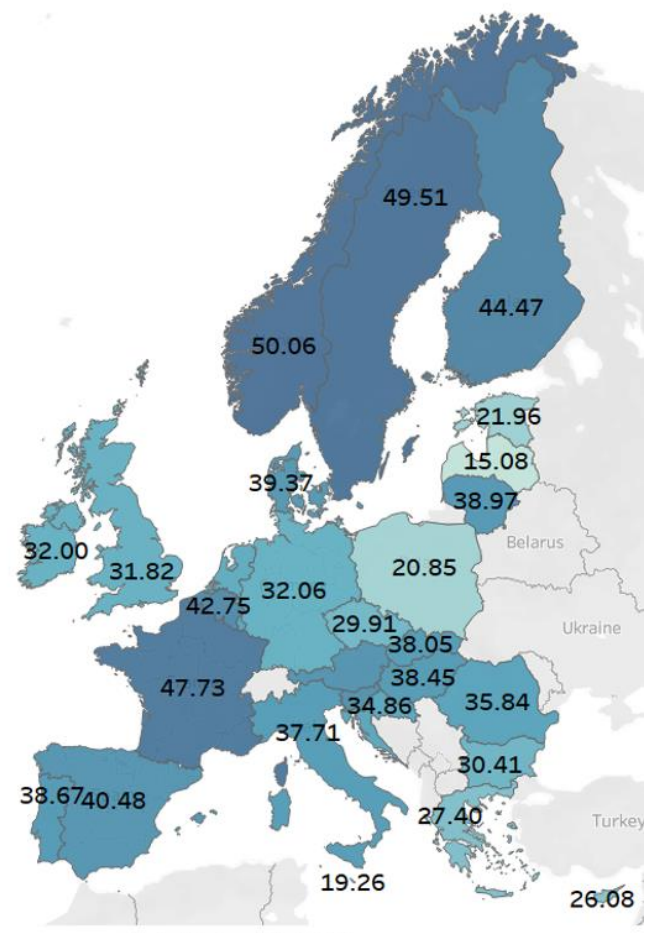

(b) Petrol MPE

Figure 9. Maximum production emissions (MPEs; measured in $\mathrm{tCO}_{2} \mathrm{eq}$ ) of an EV to environmentally outperform (a) a diesel vehicle for comparison; (b) a petrol vehicle for comparison.

The authors and the Editorial Office would like to apologize for any inconvenience caused to the readers and state that the scientific conclusions are unaffected. The original article has been updated.

\section{Reference}

1. Dillman, K.J.; Árnadóttir, Á.; Heinonen, J.; Czepkiewicz, M.; Davíðsdóttir, B. Review and Meta-Analysis of EVs: Embodied Emissions and Environmental Breakeven. Sustainability 2020, 12, 9390. [CrossRef] 